carers would have liked to have learnt about the topic, and sensitive ways to present this for potentially co-present patients. Transcripts were analysed using content analysis, and validation sought from the Carer Advisory Group (CAG) and Study Advisory Group (SAG: includes clinical experts). Follow-on workshops with current carers and patients reviewed resulting draft webpages on this topic for utility and sensitivity.

Results Carers learning preferences for 'What to expect in the future' included support with: coping with symptom changes as a patient's condition worsened, discussing 'the future' with others, accessing care and support, administrative tasks (e.g. death registration), and bereavement. Findings were validated by the CAG and SAG. Current carers and patients provided valuable feedback on drafted webpages.

Conclusion Co-developed webpages on the topic of 'What to expect in the future' covered subjects bereaved carers identified as important to learn about. Their utility and sensitivity was confirmed by current carers and patients. Follow-on work is testing the prototype website with carers, patients and health care professionals to enable refinement.

\section{P-83 CARRY ON CARING: STRUCTURED CARER SUPPORT}

Helen Birch, Catherine Ainsworth, Laura Webster. Queenscourt Hospice, Southport, UK

\subsection{6/bmjspcare-2019-HUKNC.106}

Background The multi-professional team identified the need to provide a more structured programme of support for carers.

Aim To provide a bespoke programme of support and advice to carers of patients from any services provided across the organisation, based on requirements following individual holistic assessment. This would be delivered either in a group setting or individually as appropriate.

Methods Carers were identified and the carers programme was explained to them with an invitation to attend for a personal carer's assessment. The programme is co-ordinated by the Day Services Sister.

A five-week programme is implemented, with approximately six carers attending one day a week for five consecutive weeks. Carers from patients on the inpatient unit were often unable to complete the programme but were encouraged to attend when possible. Carers accessed therapy services, social worker was available for support and advice, catering staff provided information about nourishing the whole person. Hand massage and anxiety management sessions were provided as is lunch. Care shifts were provided for patients at home by Queenscourt at Home thus enabling the carers to attend.

Conclusion Evaluations have exceeded expectations. We expected carers to be disappointed when the programme ended, however, many of them have formed support groups of their own and arranged to meet regularly. Carers feel empowered with more knowledge and skills, and many realise that taking time out for themselves should be seen as a necessity and not a guilty pleasure. Other comments include 'don't feel so alone any more' and 'I feel well cared for myself'. We will continue to run the programme and adapt it as necessary according to evaluations.

\section{$\mathrm{P}-84$ \\ THE EXPERIENCE OF HOME CARE WORKERS - A HERMENEUTIC REVIEW}

1,2Lyndsay Cardwell, ${ }^{2}$ Nancy Preston, ${ }^{2}$ Sean Hughes. 'Strathcarron Hospice, Denny, UK; ${ }^{2}$ Faculty of Health and Medicine, Lancaster University, Lancaster, UK

\subsection{6/bmjspcare-2019-HUKNC.107}

Background The systematic review examined what is the experience of home care workers caring for people with palliative and end of life care needs living at home.

Methods The review was conducted using a hermeneutic approach. The databases CINAHL, PUBMED, Social Care Online and Social Services Abstracts were searched, literature searching completed in September 2018. 1636 papers were screened by title, 424 screened by abstract with 21 studies meeting the inclusion and exclusion criteria. All included studies were appraised for quality using a critical appraisal tool.

Results Ten themes arose from the synthesis. This workforce is largely female, and financially vulnerable with a lack of employment benefits. Their working environment can be extremely challenging due to limited time to deliver care to patients and families with complex and changing needs. Management and organisational support is limited. Grief and burnout is also experienced by home care workers. There is also a lack of access to education, the literature provides no clarity in the type of education and training that is required or how this could be better accessed by home care workers. Despite this, home care workers perspective on their role demonstrates a strong sense of reward in delivering personal care and emotional support.

Conclusion This hermeneutic review demonstrates there is a need to further understand what the education and support needs of home care workers caring for people with palliative care needs in the community are.

\section{P-85 MENTAL HEALTH FIRST AID FOR HOSPICE EMPLOYEES}

Laura Shukla. St Helena, Colchester, UK

\subsection{6/bmjspcare-2019-HUKNC.108}

Background One in three of the UK workforce have been diagnosed with a mental health condition at some point in their lives with around 10 million people experiencing a mental health issue each year in the UK. Confidence in employees to discuss mental health difficulties within the workplace is low and staff need avenues to feel confident to discuss their mental health. This is compounded by the known emotional burden that hospice staff face in their work.

Aim To provide hospice staff with a named mental health first aider to support staff in identifying and discussing mental health issues bringing balance between physical and mental health.

Method Dedicated mental health first aider within the hospice workplace who is available to provide mental health first aid support through a dedicated email contact and one-to-one sessions, for all staff to attend.

Results In the first nine months since the introduction of a mental first aider within a hospice setting, a number of staff have reached out for support. Verbal feedback in all cases has been in a positive response to having the opportunity to discuss mental health issues within the workplace. 
Conclusion Providing hospice employees with a mental health first aider that can support discussion around mental health concerns is one step in opening up the importance of discussing and seeking support with mental health. This now needs to be measured in terms of impact.

\section{P-86 WE KNOW WHAT IS SAID ABOUT SCHWARTZ CENTER ROUNDS $^{\circledR}$ BUT WHAT IS SAID IN THEM?}

Chantal Meystre, Mary Abbott, Dawn Chaplin. University Hospitals Birmingham NHS Foundation Trust, Birmingham, UK

10.1136/bmjspcare-2019-HUKNC.109

Background Schwartz Center Rounds ${ }^{\circledR}$ (SCR) are facilitated, experiential, reflective opportunities in the workplace focusing on the 'human dimension' of care. Originating in America, and introduced to UK hospices and Trusts from 2009, uptake rose after the 2013 Francis Report. UK SCR focus on staff wellbeing, rather than fostering compassion. Repeated attendance enables recognition of organisational dysfunction rather than blaming the individual, with reduced self-criticism. Beneficial team and personal outcomes are reported which may address, not only patient care, but also stress, burnout and clinician suicide. Feedback, focus groups and staff surveys have been reported, but no account of SCR content, which is pertinent to their mode of efficacy.

Method Evaluation of Trust SCR content. Twenty rounds of quantitative feedback analysed using Chi-squared; 23 SCR facilitator notes analysed by Interpretative Phenomenological Analysis. Consent to share learning but not to attribute content is taken.

Results 55\% attendees doctors; 8\% nurses; 8\% Professions Allied to Medicine; 4\% other; 25\% undeclared. $71 \%$ of attendees fed back. $69 \%$ rated SCR excellent or exceptional. 'Staff developing insight into how others think and feel' rated higher than 'knowledge for patient care'. Superordinate themes: Alone and fearful; Chaos and tumult; Psychological defences; Failure and loss; Recognising humanity; Responsibility and courage; and Encouragement. 39 comments in 18/23 SCR related to death and dying. Themes: Positive fulfilment; Uncertainty and self-doubt; Frustration and futility; Guilt and regret; Facing own mortality.

Discussion SCR content reveals personal psychological coping mechanisms, empathy for patients and families, as well as the moral burden of caring for the dying and their families.

Conclusion SCR rate highly. Ward-based staff attend less. Experience is addressed more than process. SCR content demonstrated staff sharing trauma, challenge, coping, telling of courage, encouraging teamwork; and the experience of caring for the dying. Staff support mechanisms remain a priority.

\section{\begin{tabular}{l|l} 
P-87 ENGAGING VOLUNTEERS IN SCHWARTZ ROUNDS \\
\hline
\end{tabular}}

Sarah Wells, Nikki Reed, Charlotte Lindley, Hannah Nolan. Marie Curie Hospice, West Midlands, UK

\subsection{6/bmjspcare-2019-HUKNC.110}

Background Schwartz Rounds have been running at our hospice for over four years. They are now a bedrock to support staff with the emotional burden of the work we do. They run every two months and attract growing numbers from different staff groups across the hospice. There are pockets of staff who rarely attend rounds, one of these groups is volunteers. We have over 200 volunteers at the hospice and they are integral to caring for our patients.

Aims We wanted to involve more volunteers in hospice Schwartz Rounds. We are aware that they are giving their time generously and that attending additional meetings or events may be onerous. We are also aware that may of the volunteers have close patient contact, and whilst being well supported by our volunteer development officer, they may appreciate time to reflect on their work.

Methods We successfully recruited a volunteer to our Schwartz steering group. We then attended one of the regular volunteer meetings and spent a short time showing the Schwartz video and talking about Rounds. There was enough interest to organise a pop- up Round. At their next regular volunteer meeting, we ran a pop-up Round with three volunteers as storytellers - 'What energises me in my role at Marie Curie'.

Results 26 volunteers attended. The storytellers came from different roles; a chaplain, a receptionist and a helper. The discussion was lively, insightful and heart-warming. Volunteers talked about the positive effect that volunteering had brought to their lives. Evaluation was all incredibly positive with volunteers valuing the opportunity to talk about the emotional impact of their work and heightening their appreciation for others' roles. Many were keen to attend future hospice rounds.

Conclusions The pop-up Round was a real success and has, along with other measures, increased the cohesiveness of paid staff and volunteers.

\section{P-88 REFLECTIVE PRACTICE - PROVEN THEORY, NEW CAMPAIGN}

Laura Newbould-Jones. Ashgate Hospicecare, Chesterfield, UK

\subsection{6/bmjspcare-2019-HUKNC.111}

We are currently reviewing the support we have on offer to all staff and volunteers at Ashgate Hospicecare. As a hospice we are acutely aware that the trauma experienced at work can and does impact on individual health and well-being and we want to facilitate an ongoing discussion around experiences at work, for all our staff.

A recent staff and volunteer survey highlighted concerns around staff well-being and we want to make sure the support services we have in place are effective and accessible to all, and as a result we are creating a campaign to engage individuals in patient-facing roles in a discussion about clinical support and reflective practice and what it means for them.

The campaign will prompt the 'Ashgate Team' to explore the importance of supervision, support and reflective practice in relation to the parts of the role they already feel important, for example patient care - it will also give the Team a preview of the different streams of support that will be on offer as we implement a new support package, for example, clinical supervision, reflective practice sessions (both group and individual) and educational session in relation to self-care. (We currently have a successful 'Schwartz Round' programme, with sessions well attended each month).

The campaign will also reinforce the message that Ashgate Hospicecare values individual well-being and understands that individuals need the time to engage in reflection and 